infection or neurovascular damage. Two patients reported transient limitation of the 5th and 1st digit extension following a biopsy of the wrist and 1st extensor compartment tendon sheath, respectively, with no detectable tendinous ruptures on US; 1 patient had a muscular hematoma of the extensor muscles of the forearm following an elbow biopsy.

\begin{tabular}{|c|c|c|c|}
\hline & \multicolumn{3}{|c|}{ Patient \& Biopsy characteristics $(\mathrm{N}=53)$} \\
\hline Age / Female & \multicolumn{3}{|c|}{$56 \pm 18$ years $/ 34(64 \%)$} \\
\hline Diagnosis & \multicolumn{3}{|c|}{21 RA, 13 UA, 8 septic, 5 crystal, 3 PsA, 1 SpA. 2 other } \\
\hline Disease duration & \multicolumn{3}{|c|}{$5.3 \pm 7.1$ years } \\
\hline DAS28 & \multicolumn{3}{|c|}{$4.3 \pm 1.2$} \\
\hline Clinical indication & \multicolumn{3}{|c|}{42 diagnostic $(79 \%), 11$ research $(21 \%)$} \\
\hline Joint size & \multicolumn{3}{|c|}{16 large, 30 medium, 4 small, 2 bursa, 1 tendon sheath } \\
\hline Infection confirmed & \multicolumn{3}{|c|}{$3 / 42(7 \%)$} \\
\hline Immediate tolerance & \multicolumn{3}{|c|}{$29 \%$ very easy, $38 \%$ easy, $24 \%$ tolerable, $9 \%$ difficult } \\
\hline Discomfort during procedure & \multicolumn{3}{|c|}{$\begin{array}{l}36 \% \text { no disc., } 42 \% \text { mild disc., } 11 \% \text { moderate disc., } \\
5.5 \% \text { mild pain, } 5.5 \% \text { intense pain }\end{array}$} \\
\hline Increase pain medication & \multicolumn{3}{|c|}{$13(30 \%)$ in days following procedure } \\
\hline Likelihood to repeat biopsy & \multicolumn{3}{|c|}{$41 \%$ very likely, $36 \%$ likely, $9 \%$ maybe, $14 \%$ unlikely } \\
\hline Immediate $\mathrm{AE}$ & \multicolumn{3}{|c|}{$\begin{array}{c}5 \text { minor local bleeding, } 1 \text { transitory forearm } \\
\text { extensor paralysis due to anesthesia }\end{array}$} \\
\hline \multirow[t]{2}{*}{ Other AE } & \multicolumn{3}{|c|}{$\begin{array}{c}2 \text { transient digit extension limitation (D5, D1), } \\
1 \text { muscular hematoma forearm }\end{array}$} \\
\hline & Pre-biopsy & Post-biopsy & p-value \\
\hline VAS pain biopsied joint $(\mathrm{mm})$ & $62 \pm 25$ & $46 \pm 29$ & $0.001 *$ \\
\hline VAS stiffness biopsied joint (mm) & $59 \pm 30$ & $37 \pm 31$ & $0.004 *$ \\
\hline VAS swelling biopsied ioint ( $\mathrm{mm}$ ) & $61 \pm 26$ & $44 \pm 28$ & $0.007^{*}$ \\
\hline US synovial thickness score & $2.5 \pm 0.6$ & $2.2 \pm 0.8$ & 0.092 \\
\hline US Power Doppler score & $1.0 \pm 1.2$ & $1.0 \pm 1.1$ & 0.414 \\
\hline
\end{tabular}

*p-value significant at $<0.05$. AE, adverse events; D1, digit 1; D5, digit 5; DAS28, disease

activity score 28 joints; disc., discomfort; PsA, psoriatic arthritis; RA, rheumatoid arthritis; SpA spondyloarthritis; UA, undifferentiated arthritis; US, ultrasound; VAS, visual analogue scale.

Conclusions: In our center, USNB has proved to be an effective technique for collection of synovial membrane that can be used for diagnostic and research purposes. The vast majority of the procedures were well tolerated, without significant worsening of local joint symptoms or synovitis, and safe, without major adverse events. Importantly, patients' concordance to repeat a USNB was mostly high.

Disclosure of Interest: None declared

DOI: 10.1136/annrheumdis-2017-eular.4342

\section{FRI0679 WHOLE SPINE AND SIJ MRI OF PSORIATIC ARTHRITIS PATIENTS: DESCRIPTIVE STUDY OF THE SPINE, AND SACROILIAC JOINTS INVOLVEMENT IN A CROSS SECTIONAL LARGE COHORT}

V. Furer ${ }^{1}$, M. Stark ${ }^{2}$, H. Matz ${ }^{3}$, D. Levartovsky ${ }^{4}$, J. Wollman ${ }^{4}$, I. Wigler ${ }^{4}$, H. Sarbagil-Maman ${ }^{4}$, D. Paran ${ }^{1}$, I. Kaufman ${ }^{4}$, M. Anouk ${ }^{4}$, S. Borok ${ }^{4}$,

R. Zemah ${ }^{4}$, A. Broyde ${ }^{4}$, G. Flusser ${ }^{5}$, I. Druckmann ${ }^{5}$, O. Elkayam ${ }^{1}$, I. Eshed ${ }^{6}$. ${ }^{1}$ Rheumatology, Tel Aviv Medical Center, Sackler School of Medicine; ${ }^{2}$ Tel Aviv Medical Center, Tel Aviv, Israel; ${ }^{3}$ Dermatology; ${ }^{4}$ Rheumatology; ${ }^{5}$ Radiology, Tel Aviv Medical Center, Tel Aviv; ${ }^{6}$ Radiology, Sheba Medical Center, Sackler School of Medicine, Ramat Gan, Israel

Background: Detection of axial disease has important implications. Data on the structural changes of the spine and SIJ in PsA is mainly based on plain XR and MRI of SIJ. The prevalence and distribution of spinal changes in PsA as detected by MRI is largely unknown.

Objectives: To evaluate acute and structural changes in spine and SIJ by whole spine MRI performed in a consecutive clinical cohort of PsA.

Methods: Adult PsA (CASPAR criteria) patients were enrolled in the study. All underwent clinical exam, CRP, HLA-B27 tests, and MRI of the entire spine and SIJ. Spinal sagittal T1-W, STIR and semi-coronal T1-W and T2-W with fat saturation sequences of the SIJ were performed. The spine was scored for the presence of syndesmophytes, bone marrow edema (BME)/fatty corners and enthesitis. SIJS were scored (Berlin score) for the presence of BME, fatty replacement, erosions, sclerosis, and ankylosis. Findings were further categorized into active sacroilitis $\left(\right.$ ASAS $\left.^{1}\right)$, structural sacroiliitis, and spinal findings compatible with $\mathrm{SpA}$ ( $\geq 3 \mathrm{BME}$ or $\geq 4$ fatty corners ${ }^{2}$ ). All MRIs were evaluated by an experienced musculoskeletal radiologist, blinded to clinical data. Data were analyzed by SPSS Version 20.0.

Results: Ninety six patients completed the study.(Table1) Active/structural/total sacroilitis was detected in $26 \% / 11.5 \% / 37.5 \%$ of patients, respectively. Spinal SpA was demonstrated in $15.6 \%$.(Table 2) Isolated spinal changes were detected in $2.1 \%$ of the cohort. Presence of inflammatory back pain (IBP) by ASAS correlated

Table 1. Demographic and clinical data

\begin{tabular}{lc}
\hline Age (mean, yr) & $50 \pm 13$ \\
Gender M:F & $50: 46$ \\
Psoriasis/PsA duration (mean, yr) & $19 \pm 13.6 / 9 \pm 8$ \\
PASI & $3.9 \pm 8.9$ \\
ASDAS-CRP & $2.2 \pm 1$ \\
Back pain (\%)/Inflammatory back pain by ASAS (\%) & $70 \% / 30 \%$ \\
HLA-B27 (\%) & $4.4 \%$ \\
Current DMARD Tx (\%)/Current biologic Tx (\%) & $45 \% / 35 \%$ \\
\hline
\end{tabular}

with the prevalence of active sacroiliitis ( $\mathrm{p} 0.024)$ and $\mathrm{SpA}$ (axial/SIJ) ( $\mathrm{p} 0.003$ ). The extent of psoriasis severity (PASI) correlated with both SIJ and whole spine SpA changes. ( $p 0.02$ for both) Gender differences or biologic therapy did not affect the prevalence of SIJ or spine involvement.

Table 2. Whole spine MRI findings

\begin{tabular}{lc}
\hline & $\mathrm{N}(\%)$ patients \\
\hline Active Inflammatory Lesions & \\
$\geq 1$ BME corner & $22(23 \%)$ \\
$\geq 1$ posterior elements enthesitis & $4(4 \%)$ \\
Structural Lesions & $10(10.4 \%)$ \\
$\geq 1$ corner erosion & $30(31 \%)$ \\
$\geq 1$ fatty corner & $30(31 \%)$ \\
$\geq 1$ syndesmophytes & \\
Distribution of inflammatory lesions: & \\
$\quad$ Cervical $2.1 \%$, Thoracic $18.8 \%$, Lumbar $14.6 \%$ & \\
Distribution of structural lesions: & \\
$\quad$ Cervical 10.4\%, Thoracic $32.3 \%$, Lumbar $25 \%$ & \\
\hline
\end{tabular}

Conclusions: In the present PsA cohort, active and structural sacroiliitis was more prevalent vs typical spinal SpA changes. In particular, there was a paucity of $\mathrm{SpA}$ changes in the cervical spine. The most prominent axial findings included fatty corners and syndesmophytes. IBP presence and extensive skin disease correlated with $\mathrm{SpA}$ axial and SIJ changes.

\section{References:}

[1] Lambert RG. Ann Rheum Dis. 2016,75.

[2] Hermann KG. Ann Rheum Dis 2012.71.

Disclosure of Interest: None declared

DOI: 10.1136/annrheumdis-2017-eular.4444

\section{FRI0680 SYNOVIAL INTENSITY MEASURED BY ULTRASONOGRAPHY AS AN INDICATOR FOR JOINT INFLAMMATION IN RHEUMATOID ARTHRITIS PATIENTS UNDER TREATMENT}

Y. Kondo, K. Suzuki, Y. Inoue, K. Sakata, C. Takahashi, M. Takeshita, Y. Kaneko, K. Yamaoka, T. Takeuchi. Department of Internal Medicine, Division of Rheumatology, Keio University School of Medicine, Shinjuku, Tokyo, Japan

Background: Ultrasonography (US) is a useful modality that can directly visualize RA joint inflammation. Recently, brightness of thickened synovium is considered to associate with local synovitis. However the accuracy of US findings with the local pathophysiology remains uncertain since synovial biopsy could be heterogeneous depending on the biopsy site and can be influenced by various medications. On another front, synovial fluid (SF) is homogenous, easy to access and contains abundant inflammatory cytokines and growth factors, which play an important role in the local pathogenesis of RA. However, the association between SF proteins and joint US findings is not clear.

Objectives: To clarify whether synovitis detected by US including synovial hypertrophy, vascularity and brightness reflect local joint molecular pathophysiology. Methods: Forty-four RA patients were recruited. All patients were performed standardized US examination of knee joint. US images were evaluated by semi-quantitative scoring (synovial hypertrophy; grey scale (GS) US, vascularity; power Doppler (PD) US) and quantitative analysis by using Image J (National Institutes of Health, MD, Maryland USA). The average of the pixels of synovial tissue area (GS quant), PD signal area (PD quant) and mean gray values of synovium (Brightness) in 3 areas of the knee joint were calculated. US guided SF aspiration was performed on the same day and concentrations of cytokines and growth factors were measured by Cytometric Beads Array. (BD Biosciences, NJ, USA)

Results: Median age, disease duration and DAS28-ESR were 64 years, 1.5 years and 5.2 respectively. Mean GSUS and PDUS were 2.3 and 2.0. Nineteen patients were untreated. US inflammatory findings especially PD quant were well correlated with corresponding SF IL-6, IL-8, IL-1 $\beta$ and IL-10.(range of rho;0.40-0.72, $p<0.05$ ) synovial brightness also inversely correlated with SF VEGF (rho $=-0.41, \mathrm{p}<0.05$ ). When we analyzed untreated and treated RA patients separately, GS quant did not correlate with any SF cytokines in treated group although, PD quant and brightness both significantly correlated with SF IL-6 and VEGF $(p<0.05)$. Next, we divided the treated patients into 4 groups according to median of brightness and GS quant to compare the SF IL-6 levels. This analysis showed that SF IL-6 levels were influenced by synovial brightness rather than its hypertrophy. $(p<0.05)$

Conclusions: Our results suggest that not only US PD signals but also synovial brightness is a useful indicator for joint inflammation rather than synovial hypertrophy itself in treated RA patients.

References:

[1] Naredo E et al. Arthritis Rheum 2008; 58: 2248-56.

[2] Kelly S et al. Arthritis Res Ther. 2015 Mar 13;17:58.

Disclosure of Interest: None declared

DOI: 10.1136/annrheumdis-2017-eular.4285 